\title{
ChemComm
}

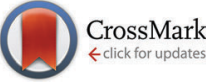

Cite this: Chem. Commun., 2014, 50,11543

Received 23rd June 2014, Accepted 7th August 2014

DOI: $10.1039 /$ c4cc04778h

www.rsc.org/chemcomm

\section{Indanthrone dye revisited after sixty years $\uparrow$}

\author{
Kamil Kotwica, ${ }^{a}$ Piotr Bujak, ${ }^{\text {a }}$ Damian Wamil, ${ }^{a}$ Mariusz Materna, ${ }^{a}$ Lukasz Skorka, ${ }^{a}$ \\ Piotr A. Gunka, ${ }^{a}$ Robert Nowakowski, ${ }^{b}$ Barbara Golec, ${ }^{b}$ Beata Luszczynska, \\ Malgorzata Zagorska ${ }^{a}$ and Adam Pron ${ }^{a}$
}

Indanthrone, an old, insoluble dye can be converted into a solution processable, self-assembling and electroluminescent organic semiconductor, namely tetraoctyloxydinaptho[2,3-a:2',3'-h]phenazine (P-C8), in a simple one-pot process consisting of the reduction of the carbonyl group by sodium dithionite followed by the substitution with solubility inducing groups under phase transfer catalysis conditions.

An impressive development of organic electronics in the past decade was inherently associated with the elaboration of new synthetic strategies leading to low and high molecular weight organic semiconductors, mainly of a fused aromatic and heterocyclic nature. ${ }^{1}$ Among the many promising approaches in the synthesis of semiconductors with tunable redox, spectroscopic and electronic properties, functionalization of oligoacenes with pyridine- or pyrazine-type moieties deserves special attention. ${ }^{1 c}$ Replacement of some methine-type carbons with nitrogen radically changes the properties of the resulting semiconductors. As indicated by Winkler and Houk ${ }^{2} N$-substituted oligoacenes may be considered as potential n-type semiconductors because of their high electron affinity $^{3}$ in contrast to oligoacenes not containing nitrogen atoms which are widely used in organic electronic devices as p-type semiconductors. ${ }^{1 a, 4}$ Moreover, $\mathrm{N}$-substituted oligoacenes are less sensitive to oxidative degradation or to dimerization processes as compared to their all carbon counterparts. ${ }^{5}$ Finally, by controlling the $\mathrm{N}$ to $\mathrm{C}$ ratio, as well as the positions of nitrogen atoms in the molecule, it is possible to prepare derivatives strongly differing in their physical properties, adapting them to a given application. ${ }^{2,6}$

\footnotetext{
${ }^{a}$ Faculty of Chemistry, Warsaw University of Technology Noakowskiego 3,

00-664 Warsaw, Poland. E-mail: piotrbujakchem@poczta.onet.pl

${ }^{b}$ Institute of Physical Chemistry, Polish Academy of Science, Kasprzaka 44/52, 01-224 Warsaw, Poland

${ }^{c}$ Department of Molecular Physics, Technical University of Lodz, Zeromskiego 116, 90-924 Lodz, Poland

$\dagger$ Electronic supplementary information (ESI) available: Experimental procedures, characterization data of P-C8, organic light emitting diode fabrication. CCDC 1006274. For ESI and crystallographic data in CIF or other electronic format see DOI: $10.1039 / \mathrm{c} 4 \mathrm{cc} 04778 \mathrm{~h}$
}

Initially developed methods for the preparation of $\mathrm{N}$-substituted acenes consist of the condensation reaction between $o$-diaminoacenes with $o$-diketones (or hydroxyketones). ${ }^{5 a, c, 7}$ Other synthetic strategies towards spatially expanded azaacenes involve a Buchwaldtype coupling between $o$-diaminoacenes with $o$-dichloroacenes. ${ }^{5 b, 8}$ More recently, a "zig-zag"'-type azaacene molecule, namely

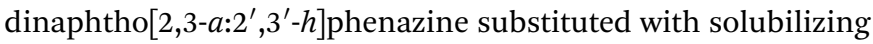
triisopropylosilylethynyl groups was obtained by the oxidative coupling of two 2-aminoanthracene molecules. ${ }^{9}$

Popular alizarin-type dyes such as indanthrone or flavanthrone are structurally strikingly similar to several azaacene semiconductors presently tested as components of organic electronic devices. ${ }^{1 c, 3 a, 10}$ In the past six decades the research interest in these compounds was very limited, and few publications described liquid crystallinity of indanthrone derivatives, ${ }^{11}$ their nonlinear optical properties, ${ }^{12}$ or their possible use as low molecular weight Bcl2 inhibitors. ${ }^{13}$ Meanwhile several new semiconductors have been obtained by functionalization of well known dyes (including natural ones). The use of isoindigo $\left((E)-1 H, 1 H^{\prime}-\left[3,3^{\prime}\right] \text { bindolylidene-2,2'-dione }\right)^{14}$ or diketopyrrolopyrrole or diketopyrrolopyrrole-derived azaacenes ${ }^{15}$ as a building block in the synthesis of solution processable organic semiconductors must be quoted here as an instructive example.

In this communication we describe the preparation and detailed characterization of a new, solution processable, electroactive conju-

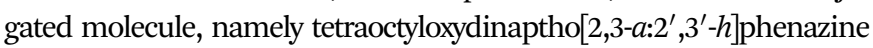
(P-C8) - tetraalkoxy-substituted indanthrone (Scheme 1). This tetraoctyloxy derivative of diazaacene, containing a phenazine-type central unit was synthesized from a well known commercially available blue dye - indanthrone - insoluble in organic solvent reagents which can be obtained from 1-aminoanthraquinone (see $\mathrm{ESI} \dagger$ ). Indanthrone is readily transformed into P-C8 in a one-pot system by carrying out the carbonyl group reduction with sodium dithionite followed by the substitution reaction under phase transfer catalysis conditions. This is a well known method, previously used for the synthesis of alkoxy derivatives of quinone moieties containing compounds,${ }^{16}$ modified here by replacing zinc with sodium dithionite.

The ${ }^{1} \mathrm{H}$ and ${ }^{13} \mathrm{C}$ NMR spectra of P-C8 are fully consistent with the condensed zig-zag dinaphtho[2,3-a:2', $\left.3^{\prime}-h\right]$ phenazine structure of $C_{2 \mathrm{~h}}$ 


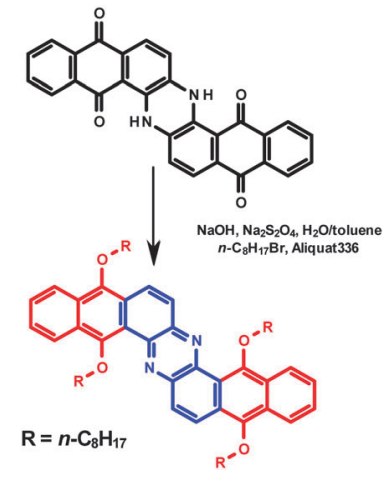

Scheme 1 Synthetic route to P-C8

(a)

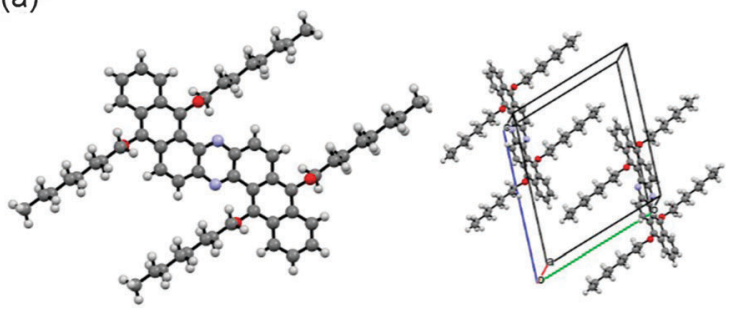

(b)

Fig. 1 (a) X-Ray crystallographic structure of P-C8. (b) Crystal structure packing of P-C8 in the unit cell $(a=9.93781(14) \AA, b=15.1528(2) \AA, c=$ $\left.17.8125(2) \AA, \alpha=69.7564^{\circ}(13), \beta=88.9555^{\circ}(11), \gamma=87.1772^{\circ}(12)\right)$.

symmetry (see ESI†). In particular two doublets can be observed in the aromatic part of the ${ }^{1} \mathrm{H}$ NMR spectrum with the coupling constant $J=9.5 \mathrm{~Hz}$ which unambiguously originate from four protons of the phenazine ring. The presence of the pyrazine ring was further corroborated by Field Desorption $\left(\mathrm{FD}^{+}\right)$and Electron Ionization $\left(\mathrm{EI}^{+}\right)$mass spectrometry, which gave molecular peaks of 893.6 and 892.7, respectively (calcd for $\left(\mathrm{C}_{60} \mathrm{H}_{80} \mathrm{~N}_{2} \mathrm{O}_{4}\right)^{+}=892.6$ ).

P-C8 readily crystallizes in THF solutions yielding good-quality single crystals suitable for crystal structure determination. There are two almost planar molecules in the triclinic unit cell (space group: $P \overline{1})$ (see Fig. 1). For details concerning crystal structure determination and the crystallographic parameters see the ESI. $\dagger$

P-C8 shows a strong tendency to form self-assembled monolayers on the surfaces of appropriate substrates such as, HOPG. Fig. 2 shows a representative STM image of a monolayer

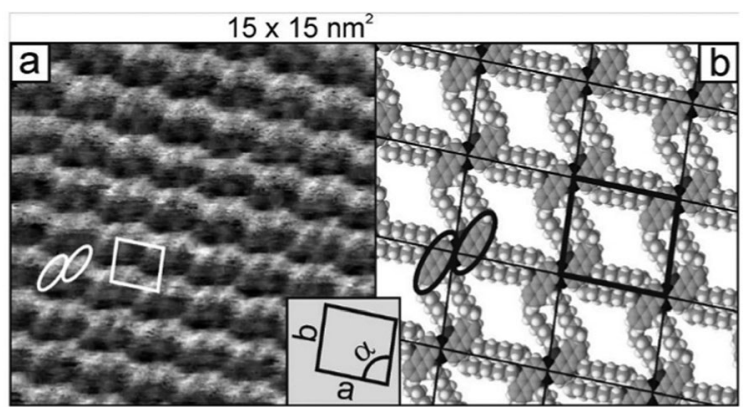

Fig. 2 (a) STM image and (b) corresponding model of adsorption geometry of a monolayer of P-C8 deposited from hexane on HOPG graphite $\left(15 \times 15 \mathrm{~nm}^{2}, I_{\mathrm{t}}=1 \mathrm{nA}, V_{\text {tip }}=-1 \mathrm{~V}\right)$. deposited from hexane solution. The unit cell parameters determined from this image are: $a=20.5 \AA, b=18.5 \AA, \alpha=87^{\circ}$ yielding a nearly rectangular $2 \mathrm{D}$ unit cell. The shape of the unit cell is in contrast to the three-fold symmetry of the graphite surface and clearly indicates that adsorbate-adsorbate interactions are a dominant factor determining the supramolecular organization of P-C8 in the monolayer. Both 2D and 3D supramolecular structures are governed by the mode of substituent interdigitation. The main difference between these organizations has its origin in a different spatial orientation of the alkoxy substituents with respect to the conjugated core. In the monolayer, both parts form the same plane whereas in the single crystals they are nearly orthogonal. As a consequence the 2D cell parameters are increased.

The redox properties of P-C8 were studied using cyclic voltammetry. Its cyclic voltammogram yields two irreversible oxidation peaks and one reduction peak (see Fig. S5 in the ESI $\dagger$ ). The HOMO and LUMO positions, determined from the electrochemical studies ${ }^{17}$ are significantly altered as compared to the case of the corresponding levels in phenazine (see Scheme 2). ${ }^{7 g} \mathbf{P}-\mathbf{C 8}$ can be considered as a DAD molecule with a central electroaccepting phenazine unit connected to two dialkoxynaphthalene donors. This chemical constitution results in a significant lowering of the electrochemical band gap from 2.91 in phenazine to $1.89 \mathrm{eV}$ in P-C8.

It is instructive to confront the electrochemical data with the plots of frontier molecular orbitals and spin densities of the radical cation and radical anion formed, respectively, upon the oxidation and reduction P-C8, obtained from quantum chemical calculations. They were performed using the Gaussian09 Revision D. $01^{18}$ package and employing the hybrid B3LYP ${ }^{19}$ exchange correlation potential combined with the $6-31 \mathrm{G}(\mathrm{d}, \mathrm{p})$ basis set. The HOMO is extended over the aromatic rings avoiding the central nitrogen atoms whereas LUMO is preferentially located on the central phenazine unit. Upon the formation of a radical cation through oxidation the spin density preferentially concentrates on the dialkoxynaphthalene D segment. Reduction of P-C8 to a radical anion moves the spin density towards the central phenazine part (see Fig. S6 in the ESI $\dagger$ ). This finding supports the DAD nature of the studied compound and explains its electrochemical properties.

In Fig. 3 the absorption spectra of indanthrone and P-C8 are shown, the latter being compared with the calculated one. In the spectrum of indanthrone one unresolved band peaking

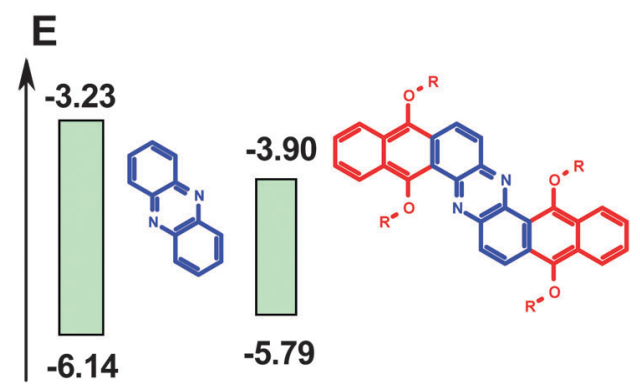

Scheme 2 Comparison of HOMO and LUMO energy levels of phenazine and $\mathbf{P}$-C8 (phenazine data are taken from ref. $\mathbf{7 g}$ ). 


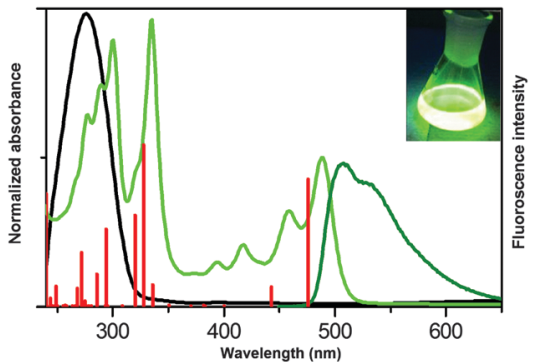

Fig. 3 Absorption spectra of indanthrone and P-C8 solutions in chloroform together with its emission spectrum. The calculated positions and relative oscillator strengths of the electronic transitions of this compound are depicted as red bars for comparison. The inset is the photograph of P-C8 solution under UV light.

at $278 \mathrm{~nm}$ is observed. For P-C8 three bathochromically shifted peaks at 300, 333 and $489 \mathrm{~nm}$ with a pronounced vibrational structure are registered. The spectrum is similar to those reported for other azaacenes ${ }^{7 g, 9,20}$ and consistent with the calculated transition (see Fig. 3 and Table S3 in the ESI $\dagger$ ). The lowest energetic band (at $489 \mathrm{~nm}$ ) is an intramolecular CT band associated with DA interactions involving charge transfer between the HOMO localized on the anthracene parts of the molecule and the LUMO located on the phenazine central part. It is worth noting that the HOMOLUMO transition is highly privileged due to the symmetry of the molecule being restricted to the centrosymmetric $\left(C_{\mathrm{i}}\right)$ point group. Since the HOMO and LUMO belong to $A_{g}$ and $A_{u}$ irreducible representations, respectively, the transition between them is highly privileged according to the Laporte selection rule. For a full analysis of the electronic transitions, a natural transition orbital analysis was performed and is included in the ESI. $\dagger$

Finally, a difference of $0.41 \mathrm{eV}$ between the optical and electrochemical band gaps should be pointed out. This is mainly associated with the exciton binding energy which in some organic compounds may reach values of up to $0.5 \mathrm{eV}^{21}$

P-C8 is photoluminescent, emitting green light with a relatively low Stokes shift of $881 \mathrm{~cm}^{-1}$ (22 nm) (see Fig. 3). The measured high photoluminescence quantum yield (56\%) together with its short lifetime (3.9 ns) prompted us to apply this derivative as an active component of "guest-host" type organic light emitting diodes. In Fig. 4 the electroluminescence spectrum of $1 \mathrm{wt} \%$ molecular

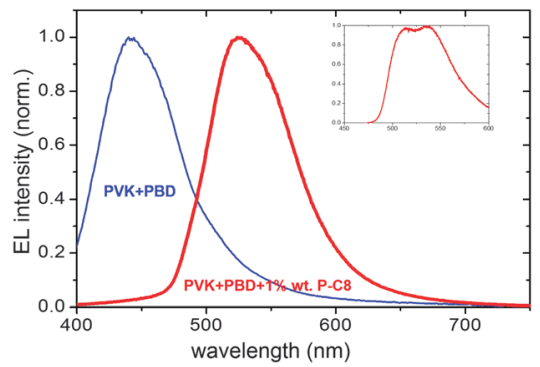

Fig. 4 Electroluminescence spectra of: 1 wt\% dispersion of P-C8 in PVK + PBD matrix (red line) and pure PVK + PBD matrix (blue line). The inset shows the zoom of the P-C8 electroluminescence spectrum over narrower spectral range. dispersion of P-C8 in a two component matrix consisting of hole transporting poly(9-vinylcarbazole) (PVK) and electron transporting 2-(4-biphenylyl)-5-(4-tert-butylphenyl)-1,3,4-oxadiazole (PBD) is compared with the spectrum of the pure matrix. It is clear that the Förster energy transfer is efficient and complete since the spectrum is characteristic of P-C8 with no features originating from the matrix (PVK + PBD). This is assured by a strong overlapping of the P-C8 absorption spectrum with the emission spectrum of the matrix.

Preliminary tests carried out on non-optimized devices of the following structure ITO/PEDOT:PSS/PVK + 1 wt $\%$ P-C8 + PBD/ $\mathrm{LiF} / \mathrm{Al}$ yield a luminance exceeding $250 \mathrm{~cd} \mathrm{~m}^{-2}$ and a luminous efficiency of $1.0 \mathrm{~cd} \mathrm{~A}^{-1}$ (for details see the ESI $\dagger$ ).

To summarize, we have demonstrated that indanthrone, an old insoluble dye, can be transformed into an interesting, solution processable semiconductor through a one-step, onepot process involving its reduction and substitution with alkoxy solubilizing groups. The self-assembling capabilities of P-C8 and its interesting luminescent and optoelectronic properties should be pointed out.

This research was carried out in the framework of the project entitled "New solution processable organic and hybrid (organic/ inorganic) functional materials for electronics, optoelectronics and spintronics" (Contract No. TEAM/2011-8/6), which was operated within the Foundation for the Polish Science Team Programme cofinanced by the EU European Regional Development Fund. The Gaussian 09 calculations were carried out in the Wroclaw Centre for Networking and Supercomputing, WSCC, Wroclaw, Poland, http://www.wcss.wroc.pl, under calculational Grant No. 283.

\section{Notes and references}

1 (a) J. E. Anthony, Chem. Rev., 2006, 106, 5028; (b) Y. Lin, Y. Li and X. Zhan, Chem. Soc. Rev., 2012, 41, 4245; (c) U. H. F. Bunz, J. U. Engelhart, B. D. Lindner and M. Schaffroth, Angew. Chem., Int. Ed., 2013, 52, 3810; (d) A. Pron, P. Gawrys, M. Zagorska, D. Djurado and R. Demadrille, Chem. Soc. Rev., 2010, 39, 2577; (e) P. Bujak, I. Kulszewicz-Bajer, M. Zagorska, V. Maurel, I. Wielgus and A. Pron, Chem. Soc. Rev., 2013, 42, 8895.

2 M. Winkler and K. N. Houk, J. Am. Chem. Soc., 2007, 129, 1805.

3 (a) Y. Xia and S. A. Jenekhe, J. Am. Chem. Soc., 2008, 130, 1118; (b) Z. Liang, Q. Tang, J. Xu and Q. Miao, Adv. Mater., 2011, 23, 1535;

(c) M. M. Islam, S. Pola and Y.-T. Tao, Chem. Commun., 2011, 47, 6356.

4 (a) J. E. Anthony, Angew. Chem., Int. Ed., 2008, 47, 452; (b) M. Watanable, Y. J. Chang, S.-W. Liu, T.-H. Chao, K. Goto, Md. M. Islam, C.-H. Yuan, Y.-T. Tao, T. Shinmyozu and T. J. Chow, Nat. Chem., 2012, 4, 574.

5 (a) B. D. Lindner, J. U. Engelhart, M. Märken, O. Tverskoy, A. L. Appleton, F. Rominger, K. I. Hardcastle, M. Enders and U. H. F. Bunz, Chem. - Eur. J., 2012, 18, 4627; (b) B. D. Lindner, J. U. Engelhart, O. Tverskoy, A. L. Aplleton, F. Rominger, A. Peters, H.J. Himmel and U. H. F. Bunz, Angew. Chem., Int. Ed., 2011, 50, 8588; (c) A. L. Aplleton, S. M. Brombosz, S. Barlow, J. S. Sears, J.-L. Bredas, S. R. Marder and U. H. F. Bunz, Nat. Commun., 2010, 1, 91.

6 Z. Liang, Q. Tang, R. Mao, D. Liu, J. Xum and Q. Miao, Adv. Mater., 2011, 23, 5514.

7 (a) U. H. F. Bunz, Pure Appl. Chem., 2010, 82, 953; (b) A. L. Appleton, S. Barlow, S. R. Marder, K. I. Hardcastle and U. H. F. Bunz, Synlett, 2011, 1983; (c) S. More, R. Bhosale, S. Choudhary and A. Mateo-Alonso, Org. Lett., 2012, 14, 4170; (d) K. K. McGrath, K. Jang, K. A. Robins and D.-C. Lee, Chem. - Eur. J., 2009, 15, 4070; (e) A. Mateo-Alonso, N. Kulisic, G. Valenti, M. Marcaccio, F. Paolucci and M. Prato, Chem. - Asian J., 2010, 5, 482; ( $f$ ) B. X. Gao, M. Wang, Y. X. Cheng, L. X. Wang, X. B. Jing and F. S. Wang, J. Am. Chem. Soc., 2008, 130, 8297; $(g)$ Y. Fogel, M. Kastler, Z. H. Wang, 
D. Andrienko, G. J. Bodwell and K. Müllen, J. Am. Chem. Soc., 2007, 129, 11743.

8 (a) D. S. Surry and S. L. Buchwald, Chem. Sci., 2011, 2, 27; (b) O. Tverskoy, F. Rominger, A. Peters, H.-J. Himmel and U. H. F. Bunz, Angew. Chem., Int. Ed., 2011, 50, 3557; (c) M. M. Payne, S. R. Parkin and J. E. Anthony, J. Am. Chem. Soc., 2005, 127, 8028; (d) J. U. Engelhart, B. D. Lindner, O. Tverskoy, F. Rominger and U. H. F. Bunz, Org. Lett., 2012, 14, 1008.

9 K. Goto, R. Yamaguchi, S. Hiroto, H. Ueno, T. Kawai and H. Shinokubo, Angew. Chem., Int. Ed., 2012, 51, 10333.

10 X.-Y. Wang, F.-D. Zhuang, R.-B. Wang, X.-C. Wang, X.-Y. Cao, J.-Y. Wang and J. Pei, J. Am. Chem. Soc., 2014, 136, 3764.

11 (a) V. V. Nazarov and E. N. Sidorenko, US Pat., 18 175, 2003; (b) O. P. Boiko, R. M. Vasyuta, O. M. Semenyshyn, Y. A. Nastishin and V. G. Nazarenko, Ukr. J. Phys. Opt., 2008, 9, 236.

12 R. Chari, S. R. Mishra, H. S. Rawat and S. M. Oak, Appl. Phys. B: Lasers Opt., 1996, 62, 293.

13 I. J. Enyedy, Y. Ling, K. Nacro, Y. Tomita, X. Wu, Y. Cao, R. Guo, B. Li, X. Zhu, Y. Huang, Y.-Q. Long, P. P. Roller, D. Yang and S. Wang, J. Med. Chem., 2001, 44, 4313.
14 E. D. Głowacki, G. Voss and N. S. Sariciftci, Adv. Mater., 2013, 25, 6783. 15 (a) C. B. Nielsen, M. Turbiez and I. McCulloch, Adv. Mater., 2013, 25, 1859; (b) W. Yue, S.-L. Suraru, D. Bialas, M. Müller and F. Würthner, Angew. Chem., Int. Ed., 2014, 126, 6273.

16 J. Hou, M.-H. Park, S. Zhang, Y. Yao, L.-M. Chen, J.-H. Li and Y. Yang, Macromolecules, 2008, 41, 6012.

17 (a) S. Trasatti, Pure Appl. Chem., 1986, 58, 955; (b) C. M. Cardona, W. Li, A. E. Kaifer, D. Stockdale and G. C. Bazan, Adv. Mater., 2011, 23, 2367; (c) R. Rybakiewicz, P. Gawrys, D. Tsikritzis, K. Emmanouil, S. Kennou, M. Zagorska and A. Pron, Electrochim. Acta, 2013, 96, 13.

18 M. J. Frisch, et al. Gaussian 09, Revision D.01, Gaussian, Inc., Wallingford, CT, 2013.

19 (a) A. D. Becke, J. Chem. Phys., 1993, 98, 1372; (b) A. D. Becke, J. Chem. Phys., 1993, 98, 5648; (c) C. T. Lee, W. T. Yang and R. G. Parr, Phys. Rev. B: Condens. Matter Mater. Phys., 1988, 37, 785.

20 S. More, S. Choudhary, A. Higelin, I. Krossing, M. Melle-Franco and A. Mateo-Alonso, Chem. Commun., 2014, 50, 1976.

21 (a) V. I. Arkhipov and H. Bässler, Phys. Status Solidi A, 2004, 201, 1152; (b) E. Ahmed, S. Subramaniyan, F. S. Kim, H. Xin and S. A. Jenekhe, Macromolecules, 2011, 44, 7207. 